\title{
Mapping Factors Influencing the Selection of Subsea Petroleum Production Systems
}

\author{
Jorge Moreno-Trejo $^{1,2}$ and Tore Markeset ${ }^{1}$ \\ ${ }^{1}$ University of Stavanger, N-4036 Stavanger, Norway \\ \{jorge.m.trejo, tore.markeset\}@uis.no \\ ${ }^{2}$ PEMEX Exploración y Producción, Ciudad Del Carmen, Campeche, México
}

\begin{abstract}
The development, design and selection of subsea petroleum production equipment and facilities are critical activities, as the decisions made will impact the success and profitability of the project. Technical, economic and government regulations are some of the factors that need to be evaluated in order to contract subsea services and procurement activities. Pre-studies need to be conducted to design the best subsea concept and to assess the development costs in order to succeed in the project execution and to keep the production rate and profits as expected. There are many factors that should be addressed before selecting the concept. By identifying and studying these aspects, the project management will be able to develop an optimum production system and select the best equipment to cover the functions needed, as well as identify health, safety, environmental and quality requirements and spare parts' availability for maintenance interventions. This will help to achieve the integrity of the installation and to reduce risks. In this paper we identify various aspects, factors and design criteria that need to be addressed in the design phase.
\end{abstract}

Keywords: Petroleum industry, Subsea installations, Production facilities, Influencing factors.

\section{$1 \quad$ Introduction}

The oil and gas industry worldwide is changing due to the introduction of new technology as well as exploitation in deeper water. The industry is striving to exploit reservoirs in the best way - both technically and economically - and to reduce operational and capital expenses in new developments. Subsea technology is increasingly being developed and used instead of building traditional platforms. Smaller fields can be exploited and interconnected to make them economically profitable, and standard technology can be used to conduct fast-track projects. However, new challenges that did not exist required in earlier projects arise during the selection of subsea production system solutions and have to be analyzed and developed.

Front-end engineering design (FEED) studies are carried out to identify possible solutions based on requirements in the various life cycle phases. Specialists from various fields are gathered to enrich the project. Reservoir characteristics, infrastructure, installation, transportation, environmental issues and subsea processing are 
analyzed in the first stage. Selecting the best production system will lessen the risk of cost overruns and delays. Analyzing and defining the health, safety, environmental and quality (HSEQ) requirements, as well as maintenance and spare parts' availability at an early stage, will increase the possibility for achieving the installation's integrity and reduce the risk of failure [1].

There are also external and non-technical factors that may impact the production concept, such as the political environment, local interests and regulations. These factors influence the decision-making process and need to be mapped. Country-specific agencies regulate international companies working in their territory, and these regulations may influence decisions and reduce the risks. Hence, the process of taking decisions on the selection of production facility solutions is not only economic and technical; local factors and laws concerning health, safety and environmental issues are also involved.

The development and exploitation of oil and gas reservoirs entails huge investment and long-term commitment. It involves establishing contracts and agreements with many service and manufacturing companies to supply the material, equipment, services and specialists required. Personnel chosen to work in the project need the experience and correct specialist knowledge to be able to analyze the reservoir characteristics, processes, technology, etc. Furthermore, the selection of equipment has to comply with technical and HSEQ requirements as well as international standards and guidelines. In cases where the technology does not exist, companies have to investigate and carry out more studies to figure out possible solutions. Hence, most often proven technology used in similar projects will be preferred over new, costly and unproven technology.

After geologists and geophysicists have analyzed the reservoir information and identified the reservoir production profile and where to place the production wells, the subsea production facilities need to be decided. Various options should be identified and assessed based on available information, and the best one selected to justify further investment.

The field development project not only has to focus on technical challenges, but also challenges related to budgeting, planning, management, statutory regulations, project documentation, contracts, etc. need to be taken care of before the project's execution. Since different points of view and experience contribute to making better decisions, a multidisciplinary team is needed with personnel who have work experience from similar projects.

Risk and costs analysis are fundamental in such development projects, as initially there is not much detailed information. During the design phase all possible risks should be assessed in order to identify and mitigate risk. Therefore, it is of utmost importance to identify and map possible factors that may affect the project and the integrity and performance of the installed subsea solution.

Definition of the development strategy in the initial stage is a key factor in system selection. The optimum production system will determine the success of the project. This phase is critical, as wrong decisions will have greater economic impact. The costs of making changes are higher after the project has moved into the execution phase.

Based on a case study, this paper maps factors for selecting the subsea production facility from a business perspective. 


\section{$2 \quad$ Mapping Factors Influencing the System Selection Process}

There are many technical components to assess in detail during the system design. However, there are three typical business drivers to analyze; namely regulatory, commercial and technical drivers. The regulatory drivers represent the authorities, legislation and standards regulating the oil and gas industry. Governmental authorities are responsible for the field exploitation in their respective countries. They set the rules for exploring and exploiting the oil and gas fields in their territory and prioritize the factors for granting permissions before petroleum activities begin.

The commercial drivers are related to the viability of the project, taking into account the oil and gas price fluctuations and the long-term economic profits, etc. The technical drivers are related to the possibility to extract hydrocarbons using the best technical solutions and following the international standards. Technical challenges are focused on how to bring the hydrocarbons from the reservoir to the customers. Developments could vary, but the principles tend to become standardized. In this paper, only some of the technical and regulatory issues and their impact from a business perspective are discussed.

\subsection{The Influence of the Regulatory Drivers}

The oil and gas industry is governed by the laws established by the state where the fields are located. Regulations are primarily focused on maintaining national sovereignty, the safety of the communities and workers, natural resources, as well as state profits in order to improve the national economy.

These drivers are at the top of the pyramid as they were written to safeguard public interests and regulate the petroleum sector. Countries manage their natural assets as they decide, and the form of carrying out some activities may vary from one government to another. Various political or local interests may therefore influence the decision process. Some countries have created separate regulatory functions and the policies, regulatory and commercial models work in autonomous entities, while others have kept a monopoly for administering their national resources [2]. These differences are related to individual countries, history, external relations and the importance they place on some factors.

For example, some countries may use their own standards for regulating technical issues in foreign oil companies but also may choose to use international standards such as ISO13628, ANSI/API 17A in order to regulate some technical activities for the operation of subsea production systems [3], [4]. In some cases, international companies have elaborated higher requirements in their processes, overwhelming local specifications in order to assure their high quality and reputation worldwide.

\subsection{Issues Affecting the Selection of the Technical Drivers}

The exploitation of a field is driven by the feasibility of technical options in order to assess the risks in the initial development phase. According to earlier experiences, there may be two, three or more technical alternatives to analyze during the concept selection, but solutions may impact more in one region than another. For example, FPSO (floating, production storage and offloading) facilities are designed to operate 
in remote locations, and for some projects this could be a viable option. However, in the USA this is not an accepted economical solution. In the USA, FPSOs are regulated by the Jones Act which states that crews must be citizens of the USA, the tankers must have at least $75 \%$ American ownership, and tankers for transporting hydrocarbons must be built in the USA [5]. This becomes a very expensive solution with high CAPEX and OPEX. However, the use of FPSOs is becoming increasingly accepted in other regions such as Brazil.

\subsection{Advantages in Using Subsea Processing Technology}

Bai and Bai [6] define subsea processing as "any handling and treatment of the produced fluids for mitigating flow assurance issues prior to reaching the platform or onshore". The processing requirements should be designed to fit with other interfaces such as drilling and flow lines. The main benefits of carrying out production with subsea technology are (Saipem CITEPH report cited in [6]):

- Reduce CAPEX and OPEX. Subsea technology could avoid the topside processing plant

- Optimize production. Small and close satellite fields could be connected to existing infrastructure

- Extend the life of mature fields by connecting to existing infrastructure

- Optimize production on the seabed

- Improve the flow assurance

- Reduce the impact on the environment

Computer-aided design programs (CAD) are used during the modeling and evaluation of production systems. However, specific and detailed information is required to be able to design the overall concept which is sometimes not complete and precise in the preliminary studies [7]. In most cases, the subsea concept is designed using the experience of similar projects. The subsea industry would like to standardize solutions worldwide to get the equipment faster from the manufacturers. However, there are special cases with extreme reservoir conditions, as well as environmental forces, where the technology could still not be available in the market.

\subsection{Identification of Factors That Influence the Selection of Subsea System}

Fields have different characteristics and vary according to the geographic location and reservoir complexity; hence, field development may involve several challenges for each case [8]. Exploitation can be carried out with several solutions, and earlier analysis will determine the best technical and economic option. The use of subsea technology for exploiting reservoirs could be an advantage.

According to NORSOK U-001 [9], a typical subsea system includes: 1) wellhead, tubing hanger, X-mas tree; 2) production control system; 3) umbilical; 4) intervention system; 5) subsea structures and piping systems; 6) flowlines, and 7) subsea processing, boosting, separation, etc.

The type of equipment selected will mainly depend on the reservoir characteristics and the environmental conditions. Facilities available close to the field could 
influence the decision-making. It is easier and faster to connect the stream production in an existing infrastructure rather than in a new one which can take more time to build and which also could have an impact on the environment. The effect of building a new facility may increase the cost per barrel by up to $50 \%$ [10].

Initially the influencing factors should be identified and assessed. Table 1 shows some of the factors to take into account to select the most feasible option.

Table 1. Factors influencing the field development strategy

\begin{tabular}{l|l}
\hline Area & Influencing factors \\
\hline Financial & CAPEX, OPEX, interest rates, exchange rates, etc. \\
Reservoir and environment & Reservoir characteristics, seabed characteristics, weather, etc. \\
Manufacturing, installation & Quality assurance, supplier selection, commissioning, testing \\
and testing & and test criteria, hand-over acceptance criteria, etc. \\
Procurement & $\begin{array}{l}\text { Technology qualification, selection of suppliers, contractors, } \\
\text { service providers, etc. }\end{array}$ \\
Operation and maintenance & $\begin{array}{l}\text { Flow assurance, operational performance assurance, technical } \\
\text { integrity, intervention services }\end{array}$ \\
\hline
\end{tabular}

The goal of obtaining the first production is usually one of the most important factors to evaluate, as it means the field could begin to generate profits. Stakeholders expect income and cash flow from the project to re-invest in the following stages or to begin other projects. Moreover, the coordination of multiple activities during the field life cycle is a challenge due its complexity. The project has several processing periods called "windows", during which many companies interact to achieve a certain goal. The window for each service company and the interfaces between each process should be carried out according to the plan; otherwise one should adjust the next activities in order to keep the project on time. During the planning phase, some delays for uncertainties should be taken into account, such as reservoir changes or the weather. On the other hand, classification and selection of the best providers is also a key factor in the success of the project.

To be able to economically assess the project, all major costs should be addressed. Around $40 \%$ of expenses are related to the cost of facilities and $60 \%$ of expenses concern the well and surface [11].

Identification of risks is essential to maintain the integrity of people and facilities. The risk analysis and the health, safety, environment and quality (HSEQ) strategy are fundamental in subsea processes.

\subsection{Selecting Facilities Suited to the Reservoir Characteristics}

Selection of subsea facilities entails several factors, and the analysis begins with the reservoir characteristics. These have a major influence on the system selection and will determine the technical characteristics of equipment.

Information about the reservoir's rock characteristics, fluid densities, pressure and flow rates allow potential areas to be identified and provide assistance for building the production profile [12]. In addition to oil and gas, the well-stream may also contain water and sand. Processing oil and gas on the seabed has several advantages as 
discussed above. By separating out as water and sand and other unwanted components on the seabed, the hydrocarbon extraction will be improved, and one may avoid the use of a topside oil or gas production facility. This may result in increased recovery and efficiency, as well as faster reservoir exploitation as compared with other solutions [13]. It also will reduce costs and increase profits.

\subsection{The Influence of the Geographical Location}

Exploitation of oil and gas reserves will be influenced by the geographic location of the reservoir. The environment and local conditions will influence the design of the subsea production facility [14]. Some of the forces affecting the equipment include the soil support capacity, seabed pockmarks and terrain characteristics, as well as equipment weight, size, shape, etc. From the soil characteristics and topography surveys one will solve some of the challenges of laying down the flowlines and pipelines. One also would be able to identify some of the factors affecting the deployment of the equipment on the seabed. The soil needs to be stable to ensure that it is able to withstand heavy equipment during the equipment deployment and later settlements.

Detailed topography and bathymetry surveys and studies are needed to map the seabed terrain. This will identify steep slopes, ravines, depressions and boulders that may restrict routes to onshore. The goal is to identify the optimum pipeline routes and to avoid obstacles and steep slopes, as well as reduce trenching activities. However, sometimes specially designed mattresses will need to be installed to stabilize the seabed. This could result in extra costs and time.

During the concept selection, one must make some assumptions in order to make preliminary subsea equipment designs, pipeline and umbilical routes for calculating the costs and to identify potential limitations such as high slopes or free span areas. On the other hand, pockmarks might not be detected in bathymetric surveys, and they could represent further potential problems (e.g. the equipment's inclination) [14].

\subsection{Waves, Currents and Weather Affecting the Subsea Installation}

Waves, currents and weather create dynamic loads that affect the subsea facilities during the whole life cycle. Therefore, facilities should be designed and prepared to support the worst conditions. Statistical data should be taken into account to predict the oceanographic behavior in the area where the equipment is going to be installed.

However, information about the environmental conditions might not be available from historical data. Therefore, surveys should be carried out and analyzed with meteorology, oceanography and hydrodynamics specialists [15]. Estimations for more extreme waves, currents and weather are generally performed by probabilistic as well as experience records in the region. In order to maintain the integrity of people and installations, the subsea system should be designed to resist stronger currents, soil movements and sliding to be able to guarantee production regularity.

\subsection{Optimizing the Reservoir Flow}

Flow assurance relates to the process of transporting the hydrocarbons from the reservoir to the processing facilities located onshore. By analyzing the hydrocarbons and 
reservoir characteristics, pipelines and production facilities can be designed which will enable the unrestricted flow of hydrocarbons from the reservoir to the onshore facilities. Flow assurance is a critical issue in system selection due to hydrate block formations in the streamlines. Injections of various chemicals and hydrate inhibitors also increase OPEX.

The low temperature on the seabed can cause conditions that affect production flow, such as slugging, scale and hydrate formations. Wellheads, jumpers and flow lines are in risk of plug formations due to the flow is through narrow spaces. Therefore, the subsea system design should be able to mitigate the flow restrictions or blockages by injecting inhibitors in the system. Other issues that should be taken into account are the possibility of hydrate formations in shut-in periods, upset conditions as result of pigging or as result of re-start operations in the well [16].

The flow assurance department makes estimations based on fluids and reservoir properties samples from logging tools or production tests, but initially there is not much information available. Otherwise, the fluid's values are taken from neighboring fields. The reservoir's analysis may include hydrate stability curves, cloud and pour point measurements, wax deposition patterns, asphaltene stability testing and a scale analysis of the water [17]. The information obtained help to select the best overall subsea solution that will fit with the flow assurance strategy, and to plan the system operation and the equipment including the chemical process needed.

One strategy has been to maintain the temperature and pressure from the well under certain levels to avoid formations. The tubing head can use a vacuum insulated tubing to improve the thermal performance in the well. The benefices are a more turndown ratio, as the flowing temperature is higher at low rates, and a faster warmup, as the tubing head is insulated and the stream fluids do not face directly low temperatures [18]. Moreover, if the subsea system receives production in better processing conditions from the well, the production can be optimized to transport it.

Assessing the flow assurance risks in the system selection phase will contribute to success the field development. Previous tests of the fluids will help to take better decisions to mitigate the flow risks, as compounds in the pipeline can cause severe operational stoppages. The analysis of aquifer areas around the reservoir is essential, as it may be contaminated by drilling mud [19]. Water injection (i.e. produce water mixed with seawater) is often used to maintain the pressure in the field, causing souring, scaling or corrosion in the subsea equipment.

Another importance issue for optimizing the reservoir flow is to avoid further interventions in the subsea system. Repairing a blockage is expensive, as it requires specialize vessels equipped with ROVs or ROTs. In extreme situations, the substitution of the blocked area may be the best economic and viable solution [17].

\subsection{Infrastructure Available}

The use of existing platforms, processing facilities and pipelines could significantly reduce the CAPEX. Exploitation of new fields tied to existent facilities using subsea technology enables the developing of projects with marginal reserves or the increasing of production in mature reserves, making them economically viable. Infrastructure available close to the site may have a high impact on the project and system selection. 


\section{Conclusions}

In this paper various factors influencing the selection of subsea petroleum production facilities have been discussed and are summarized in Figure 1. The influencing factors vary according to the strategy adopted by each oil company. In the process of selecting subsea systems, the companies focus on achieving the schedule, reducing risks or reducing costs. The business philosophy may be different, but the oil companies tend to reduce risks to maintain the integrity of people and installations.

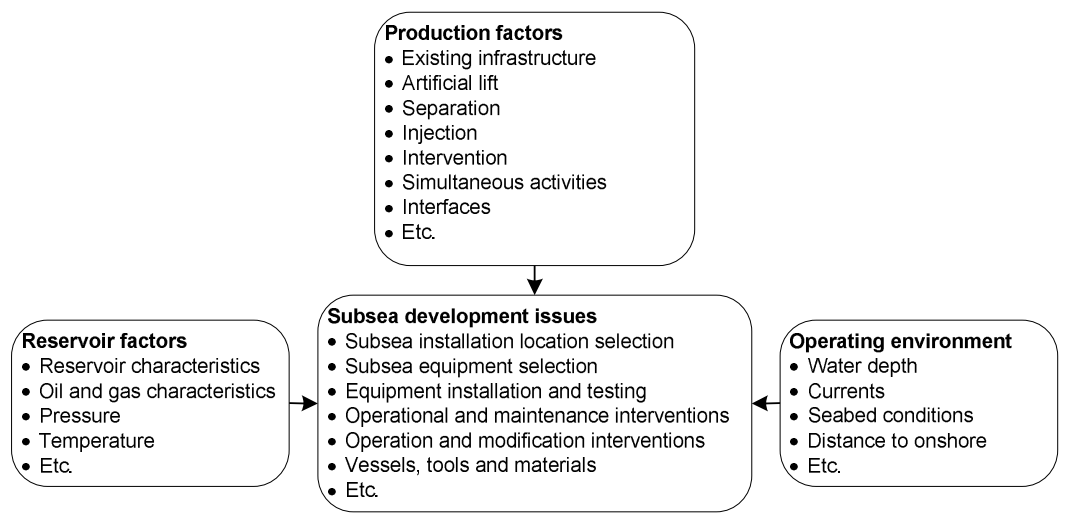

Fig. 1. Factors influencing the selection of subsea production facilities

The selection of reliable contractors is a key factor in the project's success due to their product quality and schedule goals. Oil companies may take the decision to split the processes across several service companies or to select just a few contractors to carry out the project. Having fewer contractors could entail spreading out more responsibilities and risks across fewer service companies. These decisions could increase or reduce the business risks. However, the options should be analyzed from the technical, commercial and HSEQ points of view.

The system selection entails choosing the option which fits, in the best way, with the other activities during exploitation. The schedule to obtain the first oil production could be impacted by delays in drilling activities or pipeline installation. Optimization of the field layout could improve scheduling and avoid vessels' traffic in the area. Subsea, drilling and pipeline activities could cause some interference around the wells; therefore, it is necessary to build a strategy for merging them.

The "window" for each activity may change as a result of unexpected issues such as the weather, reservoir uncertainties and, in some cases, vessels' availability. New processes are being developed to improve the current systems, taking into account stronger HSEQ practices. The selection of the optimum production system will improve business performance and stakeholder profits. 


\section{References}

1. Moreno-Trejo, J., Markeset, T.: Identifying Challenges in the Maintenance of Subsea Petroleum Production Systems. In: Frick, J., Laugen, B. (eds.) APMS 2011. IFIP AICT, vol. 384, pp. 251-259. Springer, Heidelberg (2012)

2. Thurber, M.C., Hults, D.R., Heller, P.R.P.: Exporting the Norwegian model: the effect of administrative design on oil sector performance. Energy Policy (2011), doi: 10.1016/j.enpol.2011.05.027

3. ANSI/API RP 17A. Design and Operation of Subsea Production Systems. Recommended Practice 17A, 3rd edn. American Petroleum Institute (September 2002)

4. ISO 13628. Petroleum and natural gas industries - Design and operation of subsea production systems - Part 1: General requirements and recommendations, 2nd edn. (2005)

5. Lovie, P.: FPSOs enter the Gulf of Mexico operator tool box. Journal of Petroleum Technology 62(5), 32-35 (2010)

6. Bai, Y., Bai, Q.: Subsea engineering handbook, p. 49. Gulf, Burlington (2010)

7. Woldemichael, D.E., Hashim, F.M.: Development of conceptual design support tool for subsea process equipment design. International Journal of Mechanical \& Mechatronics Engineering 9(10), 12-17 (2010)

8. Moreno-Trejo, J., Markeset, T.: Identifying Challenges in the Maintenance of Subsea Petroleum Production Systems. In: Frick, J., Laugen, B. (eds.) APMS 2011. IFIP AICT, vol. 384, pp. 251-259. Springer, Heidelberg (2012)

9. NORSOK U-001. Subsea production systems, Rev. 2 (1998) (accessed January 3, 2011)

10. Jenner, G.P., Ford, J.T., Tweedle, J.A.: Economic evaluation of subsea development options in the North Sea. Journal of Petroleum Technology, 1484-1489 (December 1991)

11. Vardeman, D., McGee, K., Kubota, R.K., Heijermans, B., Huff, J., McCurley, M., Khurana, S.: Panel: Collaboration among operators and contractors in deepwater and ultradeepwater fields. In: The Proceeding of the Offshore Technology Conference (OTC 2005), Houston, Texas, May 2-5 (2005)

12. Shell: The Petroleum Handbook. Elsevier, Amsterdam (1983)

13. Lyons, W.C., Plisga, G.J.: Standard handbook of petroleum \& natural gas engineering, 2nd edn., p. 107. Gulf, Burlington (2005)

14. Guidance Notes. Guidance notes on geotechnical investigations for subsea structures. Prepared by the Subsea Working Group of the Offshore Soil Investigation Forum, p. 8 (2000), http://sig.sut.org.uk/pdf/subseaguidancenotes.pdf, (accessed July $8,2011)$

15. ABS Guide. Guide for building and classing subsea riser systems, pp. 37-39. American Bureau of Shipping, Houston (2006)

16. Gudimetla, R., Carroll, A., Havre, K., Christiansen, C., Canon, J.: Gulf of Mexico Field of the future: subsea flow assurance. In: The Proceedings of the Offshore Technology Conference (OTC 2006), Houston, Texas, May 1-4 (2006)

17. Kaczmarski, A.A., Lorimer, S.E.: Emergence of flow assurance as a technical discipline specific to deepwater technical challenges and integration into subsea systems engineering. In: The Proceedings of the Offshore Technology Conference (OTC 2001), Houston, Texas, April 30-May 3 (2001)

18. Hudson, J.D., Dykhno, L.A., Lorimer, S.E., Shoppa, W., Wilkens, R.J.: Flow assurance for subsea wells. In: The Proceedings of the Offshore Technology Conference (OTC 2000), Houston, Texas, May 1-4 (2000)

19. Song, S.: Managing flow assurance and operation risks in subsea tie-back system. In: The Proceedings of the Offshore Technology Conference (OTC 2008), Houston, Texas, May 58 (2008) 